\title{
FUNCIONAMIENTO DISCURSIVO DE LA DEIXIS COTEXTUAL EN RELATOS CONVERSACIONALES DE HABLANTES DE LA CIUDAD DE SANTIAGO DE CUBA
}

\author{
Discursive functioning of the cotextual deixis in conversational stories of \\ speakers of the city of Santiago de Cuba
}

Tania Ulloa Casaña ${ }^{1}$

\section{RESUMEN}

El objetivo de este estudio es presentar un análisis del comportamiento discursivo de la deixis cotextual en relatos conversacionales de hablantes de la ciudad de Santiago de Cuba. Los relatos conversacionales constituyen una clase de texto oral con características peculiares en el que los deícticos espaciales organizan el universo mostrativo de lo que pretende comunicar; de ahí que estas indicaciones puedan apuntar hacia el contexto extralinguiístico o señalar, como el caso de este estudio, elementos textuales.

Palabras clave: deixis cotextual, pronombres demostrativos, adverbios demostrativos, pragmática.

\section{ABSTRACT}

The objective of this study is to present an analysis of the discursive behavior of cotextual deixis in the conversational narratives of the speakers from the city of Santiago de Cuba. The conversational narratives constitute a kind of oral text with peculiar characteristics in which the spatial deictics organize the demonstrative universe of what it intends to communicate; hence, these indications may point to the extra-linguistic context or point out, as in the case of this study, textual elements.

Key Words: cotextual deixis, demonstrative pronouns, demonstrative adverbs, pragmatics.

\section{Introducción}

La capacidad de realizar señalamientos por medio del lenguaje es una propiedad universal, como lo es, además, la existencia en las diferentes lenguas de categorías especializadas en este tipo de función. Desde la antigüedad, se ha reconocido la especificidad de ciertos términos que solo adquieren valor a través de la actualización momentánea que les confiere la producción del enunciado en que aparecen. Las "partículas" portadoras de esta función, los deícticos, alcanzan su sentido en una situación de habla concreta al ubicar referentes atendiendo a la posición relativa del hablante.

\footnotetext{
${ }^{1}$ Universidad de Oriente. Docente. Cuba. Correo electrónico: tania@uo.edu.cu

Recepción: 25-09-2017 Aceptación: 23-01-2018
} 
La presencia de los deícticos es un fenómeno medular del lenguaje, por lo que su estudio resulta en ocasiones complejo; al hablar no solamente se simboliza, sino también se señalan realidades específicas en el mundo extralingüístico, las cuales exigen para su identificación puntos de referencia que se ubiquen dentro de un determinado sistema de mostración. La elección de estas expresiones presupone el conocimiento por parte del hablante de una situación espacio-temporal dada, así como el conocimiento de un sistema lingüístico específico (el sistema de marcadores deícticos de la lengua en uso) cuyos elementos poseen condiciones contextuales muy concretas de utilización, por lo que se convierten en herramientas cómodas, económicas e irremplazables que se diseminan a través de los enunciados; su frecuencia varía en dependencia del tipo de texto y, en ocasiones, pueden estar elididas, debido a que son fácilmente deducidas del contexto o por su coincidencia con la instancia enunciativa.

Su presencia es también frecuente en los relatos conversacionales, narraciones de tipo oral que representan un evento a partir del desarrollo tempo-espacial de los acontecimientos ocurridos. Los relatos forman parte del proceso mediante el cual el sujeto se construye en sociedad y construye al mismo tiempo su realidad por lo que su presencia atiende al contexto en que aparecen y están configurados por el entorno físico donde se producen; en ellos los hablantes cuentan sus vivencias, justifican sus ideas o, incluso, apoyan los argumentos del interlocutor.

La Nueva Gramática de la Lengua Española (NGLE, 2009) define la deixis como la propiedad que poseen muchas expresiones gramaticales para denotar significados que dependen de la localización tempo-espacial de los interlocutores. Se plantea, además, en este texto, que la deixis por antonomasia es la ostensiva, ad oculos o sensible, aquella que se obtiene por simple mostración, o sea, por la presencia física de lo que se señala. Asimismo, se consideran los usos fóricos como deícticos, aunque se diferencien de los ostensivos en que convierten el texto en el espacio donde se realiza el señalamiento que caracteriza cualquiera de sus formas. Las referencias anafóricas o catafóricas constituyen, entonces, manifestaciones más abstractas de este fenómeno que se interpretan en función del vínculo que contraen con aquello a lo que se refieren. 
En el análisis que se propone, los deícticos son concebidos como "indicios de contextualización" que pueden aludir, tanto al cotexto (remisión a elementos del enunciado o intratextuales), como al contexto (elementos del acto de la enunciación o extratextuales) para crear un texto íntegro que permite guiar al receptor en su interpretación.

Lo anterior conduce, entonces, a reconocer el relato conversacional en un estudio de esta naturaleza, como parte integrante del contexto de enunciación y, como tal, puede hacer referencia a sí mismo. El espacio perceptivo es un modelo icónico para el espacio del discurso en el que los deícticos apuntan hacia un elemento textual del mismo modo que en una situación real; señalan a un objeto del mundo.

La diferencia entre un tipo de localización u otra (textual o situacional) no difiere más que en el espacio deíctico que involucra. En ambos casos, la atención se dirige hacia la realidad, señalando elementos del contexto extralingüístico o aludiendo, en otros casos, a información que ya ha aparecido (anáfora) o se encontrará de manera posterior (catáfora).

Una primera distinción básica entre las unidades deícticas se relaciona con el tipo de información deíctica. Desde este punto de vista, la deixis espacial codifica las referencias locativas de los enunciados en relación con la situación y orientación física de los participantes en el acto de habla (Escavy, 2009, p. 70).

Los pronombres demostrativos, por ejemplo, constituyen un paradigma ternario cerrado - este, ese aquel-que manifiesta una variación genérica triple - masculino, femenino y neutro- y numérica doble -singular y plural-. Son los encargados de situar en las coordenadas espaciales las entidades referidas por los sustantivos a los que determinan o sustituyen (Hipogrosso, 2001, p. 2); se convierten en índices que señalan el objeto desde el punto de origen del hablante, por lo que desarrollan una dimensión deíctica espacial articulada sobre la dimensión personal, constituyendo, de esta forma, los representantes más característicos del paradigma de las categorías deícticas (Eguren, 2000, p. 927).

Como se establece por la Real Academia Española en la Nueva gramática de la lengua española (2009, p. 328), los demostrativos, además, pueden señalar a su referente en el discurso, en un uso de referencia endofórica, la cual puede ser anafórica, cuando el demostrativo establece una relación con un referente mencionado previamente en el discurso, 
o catafórica, cuando dicha relación se presenta después del demostrativo, en tal caso, anticipa algo que será mencionado de manera posterior. Los usos fóricos de los demostrativos no dejan de ser deícticos, pues convierten el texto en el espacio en que se realiza el señalamiento.

Los adverbios demostrativos de lugar en la lengua española constituyen, por otro lado, un reducido grupo de unidades lingüísticas (aquí, ahí, allí, acá y allá) morfológicamente invariables, cuya función más habitual es la de complemento circunstancial o adjunto de un verbo (Eguren, 2000, p. 955). Esta clase de adverbios ha sido etiquetada de maneras distintas (pronominales o deícticos) resaltando, en cada caso, diversos aspectos de su semántica o sintaxis.

Su interpretación depende del lugar en que se encuentre el hablante, por lo que se relaciona con el centro deíctico de la enunciación; de esta forma, los adverbios demostrativos refieren al espacio de manera deíctica. Se organizan en dos subsistemas, uno ternario (aquí, ahí, allî) y otro binario (acá, allá). El primero manifiesta un evidente paralelismo con el sistema de pronombres demostrativos (este-aquí, ese-ahí, aquel-allí) y como estos, establece tres grados de distancia. El otro postula una relación binaria (acá, allá) y expresa proximidad o lejanía relativas con respecto al lugar en el que se encuentra el hablante (Eguren, 2000, p. 958).

Los relatos conversacionales, como antes se ha apuntado, constituyen entonces una clase de texto oral con características peculiares en el que los deícticos espaciales organizan el universo mostrativo de lo que pretende comunicar; de ahí que estas indicaciones puedan apuntar hacia el contexto extralingüístico o señalar, como el caso de este estudio, elementos textuales.

\section{La muestra}

Uno de los componentes básicos de las investigaciones de carácter lingüístico son los hablantes, pues son ellos los que aportan los materiales que integran el repertorio de datos. Considerando lo anterior, para la selección de esta se consideró que las personas fueran oriundas de la ciudad de Santiago de Cuba; de no ser así, debían tener más de veinte años de residencia permanente en dicho lugar. Con el propósito de obtener una muestra heterogénea, fueron incluidos informantes con niveles de instrucción variados, que pertenecieran a grupos etarios diferentes y de distintos sexos. 
Se decidió escoger el relato conversacional para la realización de la investigación, pues existe una carencia de estudios que aborden el comportamiento de este tipo de deixis en una situación tempo-espacial que no se corresponde con el momento de habla. Además, resulta novedoso realizar la indagación en la ciudad de Santiago de Cuba, segundo centro poblacional más importante del país y cuyos valores históricos y culturales la convierten en un sitio idóneo para cualquier pesquisa de carácter humanístico y lingüístico en particular.

La muestra se compone de treinta relatos conversacionales recogidos en cuarenta grabaciones auditivas, correspondiente a igual número de informantes, con una duración aproximada de quince minutos cada una. Para la recogida de la muestra, se estableció con cada informante una conversación semidirigida en la que la investigadora se presentó como entrevistadora participante. Esta técnica se ha revelado como un recurso de incuestionable utilidad, pues el intercambio puede conducirse como una conversación espontánea, con un grado mínimo de formalidad semejante a aquellas que pudieran surgir espontáneamente en contextos naturales.

En el período de preparación previo al inicio de las grabaciones, se dispusieron los tópicos que servirían de guía para el intercambio, puesto que el investigador es consciente de la variedad de temas sobre los cuales se puede conversar y cuáles resultan más apropiados para el interlocutor (Silva, 2001, p. 57). Las temáticas sugeridas de manera general fueron: las tradiciones histórico-culturales y populares del lugar de residencia de los informantes, sus costumbres, los gustos y aspiraciones de los informantes, sus valoraciones sobre determinados asuntos de interés, así como otras preguntas de apoyo que sirvieron como estímulo para propiciar el intercambio; aún cuando se estableció para cada sesión de grabación este patrón organizativo, se buscó en todo momento que la recogida de datos respondiera a un dinamismo interaccional.

La transcripción grafemática se subordinó al objeto y la finalidad del estudio, por tal razón, en esta investigación, se usaron las convenciones gráficas de A. Briz y el Grupo Val.Es.Co (2000).

Una vez recogida toda la información y luego de su transcripción, la cual constituye una parte fundamental del análisis, ya que implica la primera manipulación de los datos 
obtenidos, se extrajeron las expresiones deícticas objeto de estudio empleadas por los hablantes.

\section{Análisis}

El estudio de la deixis que a continuación se presenta muestra la relación entre la estructura textual y los elementos de la situación comunicativa sistemáticamente ligados a ella. Para ello, serán comentados y analizados fragmentos de los textos orales recogidos como muestra donde mejor se evidencian estos rasgos.

En el primer fragmento (1), el informante realiza una ordenación del espacio que parte primeramente del lugar de la enunciación aquí hasta situarlo en el área que servirá de escenario a los hechos contados (en la Cambula). Este desplazamiento supone una organización de las percepciones espaciales al relacionarlas en términos de distancia con el sitio aludido (un lugar apartadísimo); en el ejemplo, puede observarse, además, cómo el adverbio demostrativo allí funciona como un referente anafórico que tiene su antecedente en el enunciado que le precede (en la Cambula-un lugar apartadísimo allí); de igual forma ocurre en (2 y 3) (Venezuela allí); (en un consultorio allí). En estos casos, el mecanismo de mostración considera al texto como el espacio en el que se realiza el señalamiento al indicar cercanía cotextual y no física (un lugar apartadísimo-Venezuela-un consultorio allí):

(1) Santiago es una provincia hermosa/ yo no soy de aquí/ yo vivía en la Cambula/ un lugar apartadísimo/ allí estudié hasta el sexto grado en una escuelita donde había un solo maestro (H.G.E.II.n.m).

(2) Yo conozco a esas personas/ ellos son un grupo de investigadores que desarrollan un proyecto de investigación binacional/ así fue que en julio de 2012 nos fuimos para Venezuela// allí nos llevaron a varios centros de investigación sexual (M.G.E.II.n.m).

(3) Cuando yo me gradué de enfermera empecé a trabajar en un consultorio/ allí estuve por varios años (M.G.E.III.n.m).

En el fragmento (4), el antecedente del adverbio (allá) es resultado de una trayectoria cuyo punto final del desplazamiento coincide con la posición del hablante en el momento de la referencia (me fui a vivir con mis abuelos allá). En (5), sin embargo, allá precisa de una expresión subsiguiente que establezca las coordenadas para la localización espacial (allá $\rightarrow$ ese pueblito donde nacieron mis padres); en este caso, el pronombre demostrativo ese indica cercanía afectiva al emplearse junto al diminutivo (pueblito). Además, puede observarse un 
uso no espacial del adverbio ahí, el cual adopta, en este contexto, un significado temporal (de ahí empecé a trabajar-después empecé a trabajar):

(4) Desde niña me fui a vivir con mis abuelos y pasé toda mi juventud por allá (M.G.E.I.n.u).

(5) Todo el mundo no tiene las mismas oportunidades en la vida/ yo no tuve la posibilidad de estudiar/ te cuento/ allá yo estudié hasta el sexto grado/ de ahí empecé a trabajar/ muy joven en ese pueblito donde nacieron mis padres (H.G.E.III.n.p).

En los fragmentos que siguen, el entorno físico en que ocurre el relato permite organizar un marco de referencia que activa la presencia en los textos de adverbios demostrativos de lugar y determinadas expresiones referenciales (La Habana, Mantilla, Cuba, Martí, Cuabitas). Aquí señala tanto el punto exacto en que se encuentra el emisor como el área en que este se halla o el espacio más próximo a él, en oposición a allí y allá, que se utilizan, en ese orden, mientras más lejos se esté con respecto al hablante en el momento de la enunciación. La existencia de un antecedente es primordial para su identificación, pues permite captar el alejamiento que el adverbio indica (tocamos en Mantilla-para allá; yo voy a La Habana-que está allí); sin embargo, en algunos casos, esta cuantificación es subjetiva y relativa si se atiende al contexto real de producción del texto.

En (7), la marcación distal que se establece entre el hablante y el sitio en que se desarrolla la historia es indicada por medio de procedimientos deícticos distintos (movimiento: Yo voy a La Habana; localización: que está allí; precisión de la localización: que es Cuba); por otro lado, la expresión (que la guagua estuviera ahí mismo) se apoya en una indicación ( $\rightarrow$ parada en la puerta) que remite al lugar del enunciado (La Habana); en estos casos, se precisa de informaciones contextuales concretas que permiten al destinatario ubicar referencias ausentes del espacio enunciativo:

(6) Fuimos a La Habana y tocamos en Mantillal para allá y personas que estaban a las nueve de la noche viendo la televisión en los altos bajaban y se metían en la conga// los niños de aquel lugar nunca habían visto una conga allí/ fue muy divertido verlos bailar/ hasta los ancianos movieron los pies con ese ritmo/ tocamos casi todos los números del repertorio (H.G.E.III.n.m).

(7) Yo voy a La Habana que está allíl que es Cuba y cuando yo llego allíl después que yo veo a mi familia/ hago todas las gestiones/ doy un paseo/ yo quisiera que la guagua estuviera ahí mismo parada en la puerta para venir ya/ yo muero aquíl yo no quiero morir en ningún lado de esos// es verdad que cuando llego a La Habana y me 
erizo después que yo veo a mi familia ya yo quisiera venir para acá (H.G.E.III.n.p).

En otros casos los hablantes usaron los pronombres demostrativos neutros para vincular la línea argumental de los acontecimientos narrados con el presente de la enunciación, en (8 y 9) fueron utilizados como referente anafórico (antes del triunfo de la revolución cuando aquello; cuando yo entré a la universidad aquello):

(8) Yo nací antes del triunfo de la Revolución y no había este desarrollo que hay hoy en día// cuando aquello íbamos a la escuela casi a los siete años (M.G.E.III.n.p).

(9) Uno tiene que adaptarse en la vida a todo/ cuando yo entré a la universidad aquello fue algo impactante para mí (H.G.E.III.n.m).

En (10) la indicación hacia una dimensión interior (meterse dentro de la conga) es precisada de manera anafórica por el demostrativo (de esa cantidad de personas) actuando en este contexto como un mecanismo de cohesión textual que remite al propio discurso. En el fragmento (11), sin embargo, el mecanismo de mostración de los demostrativos (esta forma, estas actividades, esa forma) implica cercanía cotextual o discursiva y se relaciona con procesos de focalización o realce dentro del propio discurso:

(10) La conga tocaba aquí en la esquina y cuando la conga salía aquí a Martíl todo el mundo comenzaba a bailar/ habían niños que bailaban más que los grandes/ con tremendo ritmo// entonces el general Moncada/ que era del barrio/ se disfraza y se mete dentro de la conga// qué hizo el general/ un grupo de insurrectos/ una cantidad/ vinieron/ (...) pues cogieron esos palitos y los adornaban y con esos palitos ellos les daban a los españoles y como era un día permitido ellos se dejaban dar// al meterse dentro de la conga/ dentro de esa cantidad de personas/ los españoles no pueden verlo y es cuando él puede alzarse para los montes (H.G.E.II.n.u).

(11) Este reparto significaba mucho para la vida del carnaval// los vecinos de calle $K$ entre 2 da y $3 r a$ engalanaban la cuadra/ en la cual se reunía toda la juventud del reparto// era la única calle que festejaba de esta forma los carnavales// a estas actividades solo concurrían personas blancas porque las personas de color tenían sus áreas/ a las que solo ellos podían acudir y hacían de esa forma sus actividades (M.G.E.I.n.u).

En (12), eso fue cerca del momento de venir hace referencia al momento en que tuvo lugar el evento descrito en el relato (uso temporal) a partir del empleo de un demostrativo en función anafórica (visitamos el Monte Ávila, eso); el uso de (venir), implica, por tanto, la presencia del hablante en la meta del movimiento, pero en el tiempo en que se desarrollan los hechos narrados: 
(12) Se realizaron varias charlas educativas/ dialogamos así como intercambiamos experiencias sobre el trabajo que se realiza aquí en Cubal/ aparte del trabajo fuimos a lugares de interés recreativol fuimos a sitios con altos valores históricos así como museos galerías etc// uno de los lugares más interesantes que visitamos fue el Monte Ávila/l para ir hacia allá nos trasladamos en un teleféricoll subimos entre las montañas hasta la cima,/ allá hay una pista de patinaje sobre hielo/ eso fue cerca del momento de venir (M.G.E.II.n.u).

En el fragmento siguiente, se destaca el empleo del demostrativo neutro (no sale, no se comunica eso afecta) para focalizar el antecedente textual que le sirve de referente; en otro momento es usado en señalizaciones anafóricas de tipo proposicional (otro muchacho se suicidó por eso mismo; tenía el sida se suicidó por eso):

(13) Desde ese díal él se ha encerrado en su cuarto y se pasa tres y cuatro días encerrado que no sale para nada/ no sale/ no se comunica y como quiera que sea eso afecta// también/ otro muchacho que él me contó se suicidó/ se ahorcó por eso mismo porque ya tenía la enfermedad en la fase terminal/ ya tenía el sida/ que es la fase terminal del virus/ y se suicidó por eso (H.G.E.II.n.u).

En (14) el adverbio ahí tiene varios empleos; en me fui para Guantánamol/ de ahí fuimos a vivir para Palma adquiere cierto valor temporal (me fui para Guantánamol/ después fuimos a vivir para Palma) a partir de un señalamiento hacia el cotexto (Guantánamo de ahî); en otro momento, (fuimos a vivir para Palma/ de donde son mis padres y ahí estuvimos un tiempo) es usado en una referencia anafórica (en Palma ahí estuvimos):

(14)Vine para acál por solicitud de un compañero de mi esposo que estaba esperando que terminaran el edificio para nosotros mudarnos para acá pero cuando yo vi que el edificio estaba en la tercera planta cogí a mi muchachito y me fui para Guantánamo// de ahí fuimos a vivir para Palma/ de donde son mis padres y ahí estuvimos un tiempo hasta que hicieron el edificio y vinimos para acál en el noventa y cinco// en el primer año de la carrera de mi hijo debutó con una epilepsia y lo que hice fue que pedí la baja y me dedique a estar aquíl todo eso duró desde el 2003 hasta el 2010 que fue que se graduó (M.G.E.II.n.m).

En otro caso (15), se traza mentalmente el recorrido que el receptor debe realizar para reconocer el sitio en cuestión (las intersecciones de Julián del Casal/ donde dobla Pérez Andrés con lo que es Callejuela y Moncada en esa zona ahí en la esquina). En el último fragmento (16), el adverbio precisa, de forma anafórica (está en Maceoahí radica (...) ya ahí) la localización espacial que se desea destacar: 
(15) La sopa de los negros se hacía en lo que es hoy las intersecciones de Julián del Casal/ donde dobla Pérez Andrés con lo que es Callejuela y Moncada/ en esa zona/ ahí en la esquina/ había una tienda de chinos (M.G.E.II.n.m).

(16) De ahí pasaron para Rastro y San Ricardo/ luego estuvieron por San Antonio y actualmente está en Maceo/ esquina San Bartolomé/ ahí radica lo que es la Tumba Francesa/ ya ahí no existen en realidad/ ninguno de los eee (...) de los iniciadores de la Tumba Francesa (M.G.E.III.n.m).

En (17), el área donde se reunía toda la juventud señala una porción del espacio que será precisada luego de la expresión apelativa (ahí estaban las canchas); el verbo de localización (estaban) focaliza el sitio en el que se encuentra situada la entidad que refiere el hablante:

(17) Porque era el área donde se reunía toda la juventud/ tú me preguntarás que por qué toda la juventud// el problema es que ahí estaban las canchas del Instituto Preuniversitario Cuqui Bosch (M.G.E.II.n.u).

En otro caso (18), se presenta una situación hipotética en un espacio determinado que hace corresponder el hablante con una zona próxima al interlocutor (tener una relación estable con su pareja-ahî); en otro momento, el propio adverbio es empleado en una relación anafórica para realzar este segmento del enunciado (tener un desliz ahí mismo-adquiere el sida):

(18) Una persona puede tener una relación estable con su pareja ahí y// quién sabe/ tener un desliz y/ ahí mismo/ en el desliz/ adquiere el sida/ u otra enfermedad de transmisión sexual (H.G.E.II.n.m).

En el fragmento (19), el empleo de las preposiciones (para y en) indica, por un lado, el lugar al que tiende el movimiento (para meterse en la conga; estar ahî) y por otro, el sitio dentro del cual ocurre lo que expresa el significado verbal (en la conga estar ahí):

(19) Antes la gente se preparaba para meterse en la conga/ para arrollar en la conga/ las personas el día de la invasión en los carnavales se ponían un pantalón que se habían mandado hacer/ una blusa que se habían mandado hacer y sacaban toallas muy vistosas para meterse en la conga y estar ahí (H.G.E.II.n.m).

Resulta interesante en la descripción de un desplazamiento que se enmarca entre los límites de un sitio determinado (de Trinidad) y la posición que ocupa el hablante (hasta aquî), en el ejemplo (20), el empleo de un adverbio en una localización estativa (estaba ahí) que 
designa, en este caso, la cantidad de personas concentradas entre las demarcaciones espaciales antes consideradas.

(20) Parecía una invasión de Trinidad hasta aquí lo que estaba ahí/ mujeres/ niños/ hombres/ viejos/ arrollando/ y todavía no estamos en carnaval ((...)) o sea que más bien entre la juventud y la misma/ eh los antecesores de nosotros se mantiene el ritmo/ la oyen y salen (H.G.E.II.n.m).

\section{Conclusiones}

El estudio del comportamiento discursivo de la deixis cotextual en relatos conversacionales de hablantes de la ciudad de Santiago de Cuba permitió advertir que estas señalizaciones a la realidad extralingüística son de interés, tanto desde el punto de vista de la teoría gramatical como desde la óptica de su comportamiento discursivo, pues se corresponden con formas lingüísticas que adquieren plenitud referencial dentro del contexto pragmático en que son utilizadas.

El estudio realizado ha permitido mostrar que la función deíctica en los relatos conversacionales se traslada de forma significativa al texto mismo. Esta remisión hacia elementos del enunciado se relaciona con procesos de focalización que señalan continuidad con respecto a un foco de atención previamente establecido en el propio discurso, contribuyendo, de este modo, a su estructuración superficial. 


\section{Bibliografía}

Álvarez Castro, Camilo. (2012). Deixis vs. anáfora en la descripción semántica del futuro en francés. Recuperado de www.dialnet.unirioja.es/descarga/articulo/1011548.pdf

Briz, A y Grupo Val.Es.Co. (2000). Cómo se comenta un texto coloquial. Madrid: Editorial Ariel.

Cifuentes Honrubia, José Luis. (1986). Espacio y enunciación en la dinámica textual de la Lengua Española. Recuperado de www.ua.es/personal/cifu/publicaciones/Espacioyenunciacion.pdf

Escandel Vidal, María Victoria. (1993). Introducción a la Pragmática. Barcelona: Editorial Anthropos.

RAE. (2009). Nueva gramática de la lengua española. Asociación de academias de la lengua española. España: Editorial Espasa Libros.

Escavy Zamora, Ricardo. (2009). Pragmática y textualidad. España: Ediciones de la Universidad de Murcia.

Eguren, Luis J. (2000). Pronombres y adverbios demostrativos. Las relaciones deícticas. En Ignacio Bosque y Violeta Demonte (Eds.), Gramática descriptiva de la lengua española (Vol. 1). Madrid: Editorial Espasa Calpe.

García Landa, José Ángel. (s.f.). Sobre la narración conversacional. Recuperado de http: www.academia.edu/171637/Sobre_la_narracion_conversacional

Geckeler, Horst. (s.f.). Anáfora e intermediación. Recuperado de http: www.iccom1.liccom.edu.uy/docencia/lisa/articulos/anafora.html

Habler, Herda. (2009). Deixis y modalidad en textos narrativos. Recuperado de http: www.romanistik.uni-mainz.de/hispanistica.de/.../Sek-13-Hassler...pdf.

Hipogrosso, Carlos. (2001). El campo mostrativo del lenguaje: una introducción al comportamiento de los pronombres. Recuperado de http:www.old.liccom.edu.uy/.../lenguaescrita/.../EL_CAMPO_MOSTRATIVO_DE L_LENGUAJE.pdf 
Marchese, Angelo. (s.f.). Las estructuras espaciales del relato. Recuperado de http: www.cdigital.uv.mx/bitstream/123456789/6262/2/198310P25.pdf.

Martín López, María Isabel. (s.f.). Deixis frente a anáfora en griego antiguo. Recuperado de http: www.juntadeandalucia.es/...tic/.../COMPLETA_LENGUA.pdf

Nava Vásquez, Arlette. (2011). Análisis de la deixis en un texto narrativo. Recuperado de http: www.filosofia.uatx.mx/6.pdf

Silva Corvalán, Carmen Silva. (2001). Sociolingüística y Pragmática. Washington DC: Georgetown University Press.

Vílchez M., Mayela. (2004). De lo fórico a lo deíctico. Un obstáculo para escribir textos plenos. Recuperado de http: www.revistas.luz.edu.ve/index.php/lin/article/view/8743 


\section{Anexo}

\section{Anexo 1. Simbología empleada}

\begin{tabular}{ll}
\hline G.E. & Grupo etario \\
\hline $\mathrm{M}$ & Mujer \\
\hline $\mathrm{H}$ & Hombre \\
\hline $\mathrm{n}$ & Nivel de instrucción \\
\hline $\mathrm{p}$ & Primario \\
\hline $\mathrm{m}$ & Medio \\
\hline $\mathrm{u}$ & Universitario \\
\hline (Briz y & Grupo Val.Es.Co): \\
\hline / & Pausa corta inferior al medio segundo \\
\hline // & Pausa entre medio segundo y un segundo \\
\hline /// & Pausa de un segundo o más \\
\hline$((\ldots))$ & Fragmento indescifrable \\
\hline i & Interrogaciones \\
\hline (en)tonce & Reconstrucción de una unidad léxica que se ha pronunciado \\
\hline
\end{tabular}

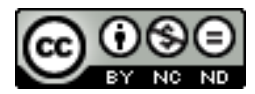

Esta obra está bajo una licencia de Creative Commons Reconocimiento-NoComercialSinObraDerivada 4.0 Internacional 